\title{
Genetic Diversity and Differentiation of Dendrocalamus membranaceus (Poaceae: Bambusoideae), a Declining Bamboo Species in Yunnan, China, as Based on Inter-Simple Sequence Repeat (ISSR) Analysis
}

\author{
Han-Qi Yang ${ }^{1, \dagger}$, Man-Yun An ${ }^{1, \dagger}$, Zhi-Jia Gu ${ }^{1, \dagger}$ and Bo Tian ${ }^{2, *}$
}

1 Research Institute of Resource Insects, Chinese Academy of Forestry, Kunming 650224, China;

E-Mails: yanghanqikm@yahoo.com.cn (H.-Q.Y.), anmanyun@yahoo.com.cn (M.-Y.A.), guzhijia139@126.com (Z.-J.G.)

2 Laboratory of Tropical Plant Resource Science, Xishuangbanna Tropical Botanical Garden, Chinese Academy of Sciences, 88 Xuefu Road, Kunming 650223, China

$\dagger$ These authors contributed equally to this work.

* Author to whom correspondence should be addressed; E-Mail: tianbo@xtbg.ac.cn; Tel.: +86-871-5160669; Fax: +86-871-5140420.

Received: 5 January 2012; in revised form: 22 March 2012 / Accepted: 31 March 2012 /

Published: 10 April 2012

Abstract: Dendrocalamus membranaceus Munro is a woody bamboo with a high economic and ecological value that often occurs as natural stands, such as in the large-scale forested areas of China's Yunnan Province. Due to its overexploitation, the habitat of D. membranaceus in Yunnan has been dramatically reduced, and the quality of the stands has declined. As a preliminary analysis in considering the effective protection for these germplasm resources, we assessed the genetic diversity of 12 natural populations in Yunnan, using inter-simple sequence repeat (ISSR) markers. From 10 ISSR primers, we generated 155 bands, of which 153 were polymorphic (98.71\%). Compared with other species in the genus, this species demonstrated a greater genetic diversity $(S=0.349)$ and lower genetic differentiation $\left(G_{\mathrm{ST}}=0.252\right)$. Our analysis of molecular variance revealed that the genetic differentiation among the populations is significant. A large proportion of the genetic variation $(78.95 \%)$ resides among the individuals within populations, whereas only $21.05 \%$ are found among populations. Mantel tests indicated no significant correlation between genetic and geographic distances among the populations. Given the low sexual reproducibility and characteristics of monocarpic plants, we recommend implementing 
in situ conservation measures for all of the D. membranaceus populations in Yunnan and collecting sufficient samples for ex situ conservation. Furthermore, the conservation area should be extended to its main natural habitats, the Lancang-Mekong River Valley.

Keywords: Dendrocalamus membranaceus; genetic variation; ISSR; population structure

\section{Introduction}

Dendrocalamus membranaceus Munro is one of the most frequently occurring, clump-forming woody bamboos (with pachymorph rhizomes) in Southeast Asia. It is naturally distributed in Laos, Myanmar, Northern Vietnam and Northern Thailand [1-3] in addition to China's Yunnan Province, especially along the Lancang-Mekong River Valley [4]. This species can grow to $20 \mathrm{~m}$ tall and $10 \mathrm{~cm}$ in diameter, and is economically important as a vegetable crop and as raw material for furniture, construction, and industrial paper pulp. Its natural habitat is a tropical mixed deciduous or monsoon forest below $1000 \mathrm{~m}$ elevation $[3,4]$.

In 1995, Yunnan Province had approx. $70,000 \mathrm{hm}^{2}$ of natural D. membranaceus forest, which provided important support for the local ecosystem, including uses as a food resource (bamboo shoots and young culms) and as habitat for the wild Asian elephant [5]. As a priority species, this bamboo has been crucial in efforts toward the protection of local soils and biodiversity in the southern and western portions of the province [6]; however, because most of its native habitat does not exist in nature reserves, this species has long been overexploited in Yunnan. For example, during the past two decades, the development of tropical agriculture plantations for rubber [7] and tropical fruits has meant that the area traditionally comprising stands of D. membranaceus has been dramatically reduced, to less than $30,000 \mathrm{hm}^{2}$ in 2008 , with obvious degradation of the quality of the remaining forest [8]. This has raised great environmental questions about water loss, soil erosion, and a decline in biodiversity [6,7]. Therefore, protective measures, in addition to germplasm collections, are desperately needed.

Woody bamboos are presumably ancient polyploids, and Dendrosalamus is regarded as hexaploid [9]. According to the Scientific Database of China Plant Species [10], the chromosome number of D. membranaceus collected from Yunnan is $2 n=70$. However, the chromosome number of paleotropical woody bamboo is generally variable, and $2 n=70 \pm 2$ is the most frequently found in Dendrocalamus [11]. If $\mathrm{x}=12, D$. membranaceus is most likely hexaploid. Recent work using dominant genetic markers has shown that plant polyploids possess a high genetic diversity $[12,13]$. However, D. membranaceus has been subjected to a severe reduction in its natural distribution, and, in general, woody bamboos reproduce clonally, two conditions that can decrease the levels of genetic variation. Thus, D. membranaceus is a good model organism for understanding how bamboos genetically change under declining situations.

Although a strict reliance on vegetative features for the traditional identification of bamboo species and cultivars has seriously limited the ability of researchers to examine their genetic variation and differentiation [14-17], molecular-marker approaches are now being adopted, including random amplified polymorphic DNA (RAPD) [18], simple sequence repeats (SSRs) [19], and inter-simple sequence repeats (ISSRs) [20]. Because the ISSR technique is easily applied, identifies high 
polymorphism and displays acceptable reproducibility, it is widely used in current studies of population genetics [21-23]. In this study, we employed ISSRs to estimate the degree of genetic variation and differentiation among 12 populations of D. membranaceus in Yunnan Province, China (Table 1). Our objective was to use this information to help understand the genetic background of D. membranaceus and also to provide a reference for the incorporation of genetic resources when devising programs for species protection and breeding.

Table 1. Populations of Dendrocalamus membranaceus examined in the ISSR analysis.

\begin{tabular}{clccc}
\hline $\begin{array}{c}\text { Population } \\
\text { Code }\end{array}$ & \multicolumn{1}{c}{$\begin{array}{c}\text { Location in } \\
\text { Yunnan Province }\end{array}$} & $\begin{array}{c}\text { Elevation } \\
(\mathbf{m})\end{array}$ & $\begin{array}{c}\text { Sample Size } \\
\text { (Number of } \\
\text { Clumps) }\end{array}$ & Geographic Coordinates \\
\hline YJ & Tongbiguan, Yingjiang & 310 & 20 & $24^{\circ} 26^{\prime} 32^{\prime \prime} \mathrm{N}, 97^{\circ} 32^{\prime} 51^{\prime \prime} \mathrm{E}$ \\
XP & Gasa, Xinping & 660 & 20 & $24^{\circ} 21^{\prime} 03^{\prime \prime} \mathrm{N}, 101^{\circ} 37^{\prime} 50^{\prime \prime} \mathrm{E}$ \\
GM & Mengding, Gengma & 532 & 20 & $23^{\circ} 30^{\prime} 25^{\prime \prime} \mathrm{N}, 99^{\circ} 01^{\prime} 13^{\prime \prime} \mathrm{E}$ \\
PR & Simaogang, Pu'er & 636 & 20 & $22^{\circ} 29^{\prime} 24^{\prime \prime} \mathrm{N}, 100^{\circ} 35^{\prime} 32^{\prime \prime} \mathrm{E}$ \\
MY & Mengyang, Jinghong & 905 & 20 & $22^{\circ} 08^{\prime} 38^{\prime \prime} \mathrm{N}, 100^{\circ} 53^{\prime} 18^{\prime \prime} \mathrm{E}$ \\
YW & Yiwu, Mengla & 844 & 20 & $22^{\circ} 06^{\prime} 13^{\prime \prime} \mathrm{N}, 101^{\circ} 25^{\prime} 36^{\prime \prime} \mathrm{E}$ \\
JH & Jinghong, Jinghong & 638 & 20 & $22^{\circ} 03^{\prime} 04^{\prime \prime} \mathrm{N}, 100^{\circ} 43^{\prime} 03^{\prime \prime} \mathrm{E}$ \\
MB & Manbian, Mengla, & 550 & 20 & $21^{\circ} 55^{\prime} 17^{\prime \prime} \mathrm{N}, 101^{\circ} 16^{\prime} 39^{\prime \prime} \mathrm{E}$ \\
ML & Menglong, Jinghong & 723 & 20 & $21^{\circ} 46^{\prime} 18^{\prime \prime} \mathrm{N}, 100^{\circ} 45^{\prime} 41^{\prime \prime} \mathrm{E}$ \\
GL & Guanlei, Mengla & 785 & 20 & $21^{\circ} 39^{\prime} 29^{\prime \prime} \mathrm{N}, 101^{\circ} 22^{\prime} 41^{\prime \prime} \mathrm{E}$ \\
MZ & Manzhuang, Mengla & 625 & 20 & $21^{\circ} 29^{\prime} 32^{\prime \prime} \mathrm{N}, 101^{\circ} 34^{\prime} 22^{\prime \prime} \mathrm{E}$ \\
MM & Mengman, Mengla & 788 & 20 & $21^{\circ} 21^{\prime} 41^{\prime \prime} \mathrm{N}, 101^{\circ} 20^{\prime} 19^{\prime \prime} \mathrm{E}$ \\
\hline
\end{tabular}

\section{Results and Discussion}

\subsection{Genetic Diversity within Populations of Dendrocalamus membranaceus}

Of the 79 ISSR primers used, 10 produced polymorphism; overall, the band reproducibility of these 10 primers is $93 \%$ (Table 2). Figure 1 presents the polymorphic fingerprinting pattern for the Mengyang (MY) population, as generated by ISSR primer UBC810. The 10 primers produced 155 reproducible bands in 240 clumps, for an average of 15.5 bands per primer. We considered each clump as a potential genet and the culms within as ramets of a clone, according to McClure [24]. Of the 155 bands, 153 were polymorphic (99\%) at the species level. The average percentage of polymorphic bands (PPB) was 48.06\%, ranging from 39\% (Xingping, XP and Guanlei, GL) to 55\% (Gengma, GM) at the population level (Table 3). Assuming a Hardy-Weinberg equilibrium, the expected diversity was estimated to be 0.164 at the population level and 0.219 at the species level. Shannon's indices of diversity were 0.249 (population) and 0.349 (species). Among our 12 populations, GM exhibited the highest degree of variability (expected heterozygosity, $H_{\mathrm{E}}=0.186$; Shannon's diversity index, $S=0.279)$, whereas GL had the lowest $\left(H_{\mathrm{E}}=0.146, S=0.216\right.$; Table 3$)$. 
Table 2. Sequences and numbers of bands for 10 primers.

\begin{tabular}{cccccc}
\hline Primer & $\begin{array}{c}\text { Sequence } \\
\mathbf{5}^{\prime} \rightarrow \mathbf{3}^{\prime}\end{array}$ & $\begin{array}{c}\text { No. of } \\
\text { Amplified } \\
\text { Bands }\end{array}$ & $\begin{array}{c}\text { \% } \\
\text { Reproducibility of } \\
\text { Bands }\end{array}$ & $\begin{array}{c}\text { No. of } \\
\text { Polymorphic } \\
\text { Bands }\end{array}$ & $\begin{array}{c}\text { \% Polymorphic } \\
\text { Bands (PPB) }\end{array}$ \\
\hline UBC 807 & $(\mathrm{AG})_{8} \mathrm{~T}$ & 19 & 95 & 18 & 95 \\
UBC 810 & $(\mathrm{GA})_{8} \mathrm{~T}$ & 17 & 92 & 17 & 100 \\
UBC 841 & $(\mathrm{GA})_{8}$ YC & 18 & 94 & 18 & 100 \\
UBC 853 & $(\mathrm{TC})_{8}$ RT & 13 & 94 & 13 & 100 \\
UBC 855 & $(\mathrm{AC})_{8} \mathrm{YT}$ & 15 & 96 & 14 & 93 \\
UBC 857 & $(\mathrm{AC})_{8} Y \mathrm{YG}$ & 12 & 91 & 12 & 100 \\
UBC 859 & $(\mathrm{TG})_{8} \mathrm{RC}$ & 16 & 93 & 16 & 100 \\
UBC 864 & $(\mathrm{ATG})_{6}$ & 15 & 90 & 15 & 100 \\
UBC 873 & $(\mathrm{GACA})_{4}$ & 18 & 92 & 18 & 100 \\
UBC 878 & $(\mathrm{GGAT})_{4}$ & 12 & 88 & 12 & 100 \\
Total & & 155 & 93 & 153 & 99 \\
\hline
\end{tabular}

Figure 1. Genetic profile of Mengyang (MY) population using primer UBC810 (as described in Table 2). Lane $C$ represents the blank control and lanes 1-20 represent template DNA for each individual from MY.

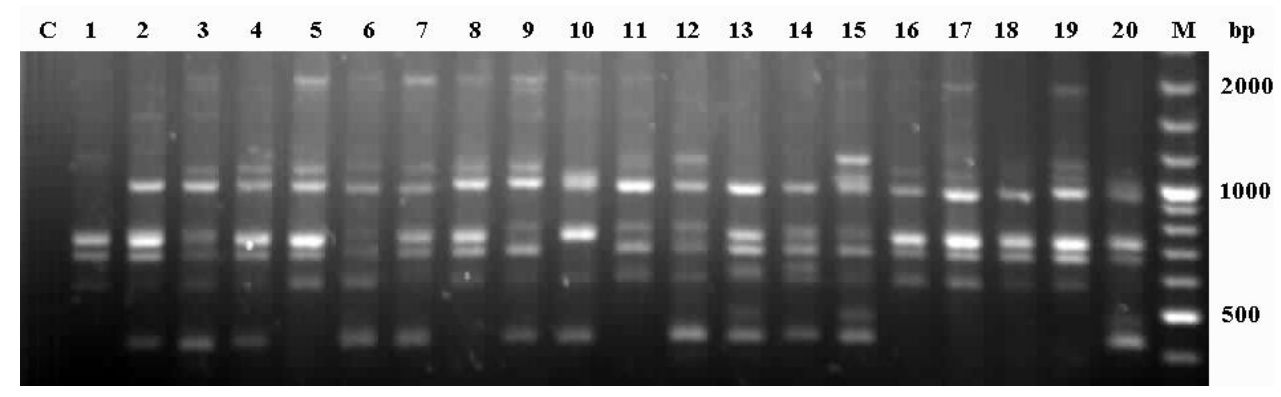

Table 3. Genetic variability within populations of Dendrocalamus membranaceus.

\begin{tabular}{ccccc}
\hline $\begin{array}{c}\text { Population } \\
\text { Code }^{\text {a }}\end{array}$ & $\begin{array}{c}\text { \% Polymorphic Bands } \\
\text { (PPB) }\end{array}$ & $\begin{array}{c}\text { Expected } \\
\text { Heterozygosity } \\
\boldsymbol{H}_{\mathbf{E}} \text { (SD) }\end{array}$ & $\begin{array}{c}\text { Shannon's } \\
\text { Diversity Index } \\
\boldsymbol{S} \text { (SD) }\end{array}$ & $\begin{array}{c}\text { Number of } \\
\text { Private Bands }\end{array}$ \\
\hline YJ & 49 & $0.165(0.194)$ & $0.248(0.281)$ & 2 \\
XP & 39 & $0.150(0.205)$ & $0.219(0.293)$ & 0 \\
GM & 55 & $0.186(0.202)$ & $0.279(0.287)$ & 4 \\
PR & 50 & $0.167(0.194)$ & $0.252(0.280)$ & 2 \\
MY & 49 & $0.173(0.199)$ & $0.259(0.287)$ & 3 \\
YW & 51 & $0.179(0.201)$ & $0.267(0.288)$ & 0 \\
JH & 47 & $0.156(0.192)$ & $0.236(0.277)$ & 0 \\
MB & 52 & $0.176(0.204)$ & $0.263(0.290)$ & 7 \\
ML & 51 & $0.162(0.191)$ & $0.264(0.275)$ & 3 \\
GL & 39 & $0.146(0.199)$ & $0.216(0.287)$ & 2 \\
MZ & 50 & $0.162(0.192)$ & $0.246(0.277)$ & 1 \\
MM & 45 & $0.147(0.187)$ & $0.220(0.272)$ & 0 \\
Mean (SD) & 48 & $0.164(0.013)$ & $0.249(0.021)$ & \\
\hline
\end{tabular}

${ }^{\mathrm{a}}$ Population codes are explained with Table 1. 
Furthermore, a high level of genetic diversity was found for this species ( $\mathrm{PPB}=99 \%, H_{\mathrm{E}}=0.219$, $S=0.349$ ). By comparison, the mean within-population gene diversity among monocotyledons is 0.144 for Nei's expected heterozygosity [25].

The high genetic diversity detected for D. membranaceus may be a consequence of its evolutionary history and the geological development of South Yunnan. D. membranaceus is most likely an ancient hexaploid [9,11], and polyploid taxa typically display a great genetic diversity, both in terms of heterozygosity and the number of bands amplified [13]. However, the habitat of the species has not suffered major geological disasters since the Tertiary period. The region is also warm and humid and provides the appropriate conditions for the reproduction of tropical bamboos [26]. Moreover, the natural populations were not, as a whole, disturbed by human activities until recently $[5,6]$. Therefore, we speculate that (1) the ancestors of D. membranaceus have accumulated abundant genetic diversity within an extensive and continuous distribution in Yunnan; (2) the existing population retains the genetic diversity from their ancestors; and (3) the habitat fragmentation caused by human activities does not perturb the genetic base of the existing D. membranaceus populations.

\subsection{Genetic Structure and Differentiation Among Populations}

The results from our analysis of molecular variance (AMOVA) showed that a large proportion of the genetic variation (78.95\%) existed among individuals within the populations, and that $21.05 \%$ resided among the populations. The genetic differentiation among the populations was significant $(p<0.001)$ (Table 4). Consistently, Nei's [27] estimator of population substructure also indicated a moderate level of population differentiation (coefficient of gene differentiation, $G_{\mathrm{ST}}=0.252$ ). Furthermore, 24 private bands were found in eight populations (Table 3), implying that some genetic difference existed among the populations.

Table 4. Analysis of molecular variance (AMOVA) for inter-simple sequence repeat (ISSR) variation for Dendrocalamus membranaceus populations.

\begin{tabular}{lcccccc}
\hline $\begin{array}{c}\text { Source of } \\
\text { Variation }\end{array}$ & $\begin{array}{c}\text { Degrees of } \\
\text { Freedom }\end{array}$ & $\begin{array}{c}\text { Sum of } \\
\text { Squares }\end{array}$ & $\begin{array}{c}\text { Mean } \\
\text { Squares }\end{array}$ & $\begin{array}{c}\text { Variance } \\
\text { Components }\end{array}$ & $\begin{array}{c}\text { \% Total } \\
\text { Variance }\end{array}$ & $\boldsymbol{p}$-Value \\
\hline Among populations & 11 & 114.58 & 10.42 & 0.44 & 21.05 & $<0.001$ \\
Within populations & 228 & 375.0 & 1.64 & 1.64 & 78.95 & $<0.001$ \\
Total & 239 & 489.58 & & 2.08 & & \\
\hline
\end{tabular}

Many factors can determine the genetic structure of plant populations, including the reproductive biology [28], and gene flow. Many RAPD- and sequence tagged microsatellite sites (STMS)-based analyses showed that long-lived, out-crossing taxa retained most of their genetic variability within populations [29]. The woody bamboos have a long vegetative phase of 20-150 years [1-3], and are typical long-lived species of the grass family. As one of those critical influences, the out-crossing of a plant species tends to explain 10 to $20 \%$ of the genetic variation among populations, whereas the selfing of a species leads, on average, to $50 \%$ variation between populations [25]. D. membranaceus can reproduce via seed in the wild, although this phenomenon is rare, and the rate of seed set is low $[3,16]$. We found a few young seedlings in the Jinghong (JH) population (Figure 2). Furthermore, studies on the floral biology have indicated that $D$. membranaceus is likely anemophilous and prone to 
be an out-crosser [16], which also was supported by the genetic differentiation $\left(G_{\mathrm{ST}}=0.252\right)$ that was similar to the average of out-crossing species $\left(G_{\mathrm{ST}}=0.22\right)$ [29].

Figure 2. Young seedlings of Dendrocalamus membranaceus in Jinghong (JH) population.

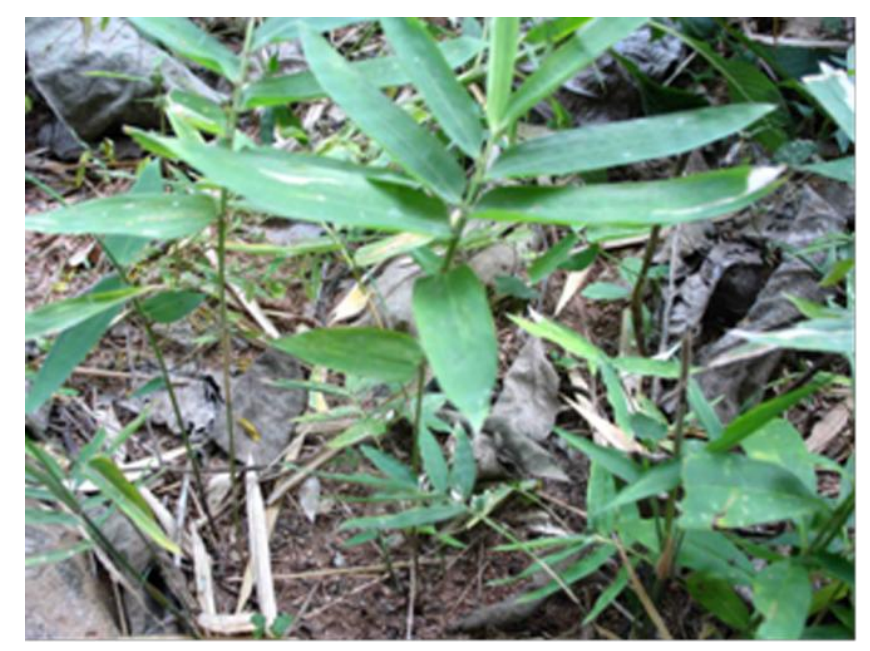

Therefore, extensive longevity and predominant out-crossing may be two important factors for the genetic structure of the existing D. membranaceus in Yunnan.

\subsection{Genetic Distances and UPGMA Analysis}

Our UPGMA tree (Figure 3), based on the values for the genetic distance $D$, revealed that the 12 populations could be separated into two clusters: XP plus Mengman (MM) and the other 10. We found no agreement with the geographic distance, which was supported by our Mantel test results, demonstrating that $D$ was not significantly correlated with the geographic distance $(r=0.197$, $p=0.184$ ) (Table 5, Figure 4). This outcome could have reflected the possibility that the examined populations of $D$. membranaceus still represented the abundant genetic variation of their ancestors. In fact, this tendency is reinforced by the naturally long vegetative phase and low seed set over the life cycle, which are typical features of woody bamboos [11,30,31]. Another possibility may be that, as an economic importance species, D. membranaceus most likely has undergone human-mediated movement of genotypes among partial or complete distribution areas, especially within those populations comprising small areas, such as XP, GM and Yingjiang (YJ). 
Figure 3. UPGMA dendrogram based on Nei's (1972) genetic distances among 12 populations of Dendrocalamus membranaceus.

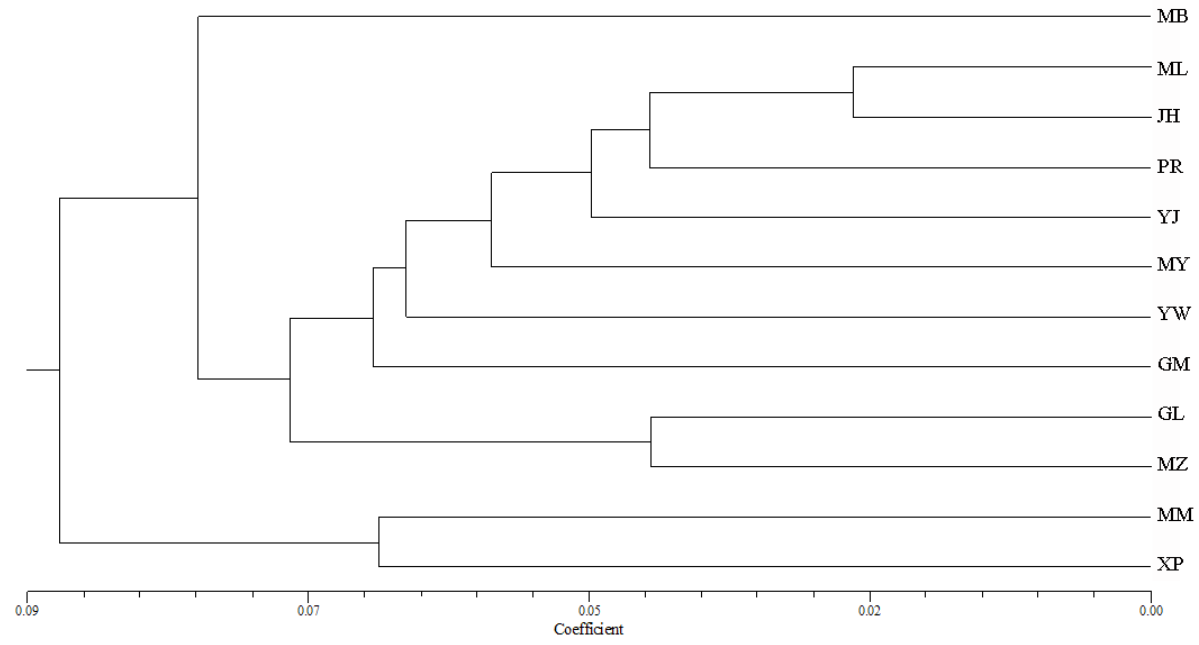

Table 5. Geographic distance $(\mathrm{km})$ (above diagonal) and genetic distance (below diagonal) between populations of Dendrocalamus membranaceus.

\begin{tabular}{lllllllllllll}
\hline & YJ $^{\text {a }}$ & XP & GM & PR & MY & YW & JH & MB & ML & GL & MZ & MM \\
\hline YJ & - & 411 & 203 & 380 & 408 & 470 & 404 & 495 & 447 & 512 & 529 & 523 \\
XP & 0.094 & - & 261 & 238 & 252 & 239 & 261 & 296 & 320 & 314 & 325 & 334 \\
GM & 0.060 & 0.103 & - & 178 & 207 & 268 & 203 & 294 & 252 & 311 & 328 & 324 \\
PR & 0.050 & 0.109 & 0.071 & - & 30 & 96 & 30 & 117 & 92 & 135 & 151 & 149 \\
MY & 0.062 & 0.099 & 0.067 & 0.067 & - & 74 & 12 & 87 & 69 & 105 & 121 & 119 \\
YW & 0.064 & 0.116 & 0.074 & 0.073 & 0.075 & - & 84 & 57 & 106 & 74 & 86 & 94 \\
JH & 0.052 & 0.091 & 0.063 & 0.049 & 0.040 & 0.056 & - & 92 & 63 & 108 & 125 & 121 \\
MB & 0.084 & 0.150 & 0.101 & 0.048 & 0.091 & 0.087 & 0.072 & - & 74 & 18 & 34 & 38 \\
ML & 0.048 & 0.113 & 0.072 & 0.041 & 0.063 & 0.058 & 0.029 & 0.062 & - & 80 & 94 & 82 \\
GL & 0.095 & 0.105 & 0.104 & 0.083 & 0.091 & 0.094 & 0.060 & 0.101 & 0.069 & - & 17 & 20 \\
MZ & 0.053 & 0.099 & 0.088 & 0.063 & 0.070 & 0.062 & 0.050 & 0.090 & 0.052 & 0.045 & - & 16 \\
MM & 0.072 & 0.066 & 0.086 & 0.069 & 0.072 & 0.094 & 0.049 & 0.102 & 0.064 & 0.086 & 0.074 & - \\
\hline & & & & \multicolumn{2}{c}{ a Population codes are explained with Table 1 } & & &
\end{tabular}

Figure 4. Correlation between geographic distance and genetic distance for 12 populations of Dendrocalamus membranaceus.

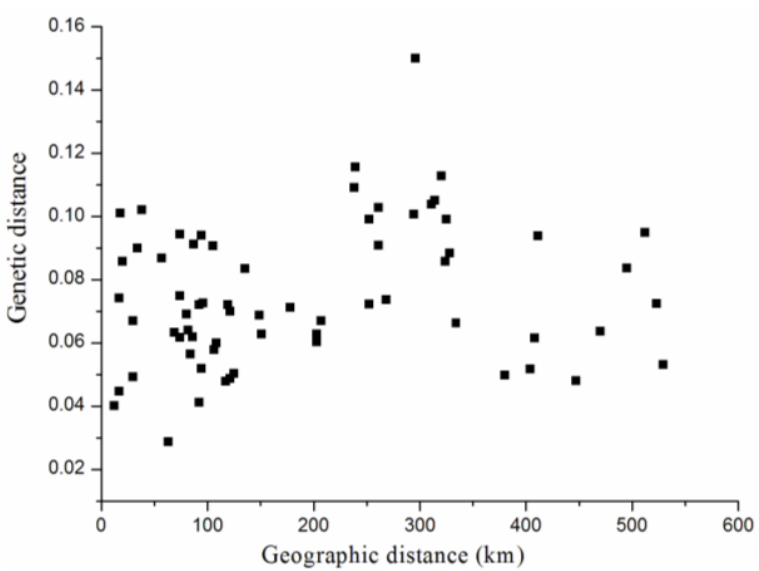




\subsection{Implications for the Development of $\mathrm{D}$. membranaceus}

The natural resources of D. membranaceus in Yunnan Province have been overexploited for many years, leading to the deterioration of its habitat $[6,8]$. The same situation has also occurred in other regions of the Lancang-Mekong River Valley, such as Myanmar and Northern Vietnam [7]. Although bamboo is of important significance for the local ecological and agricultural systems, the increasing demand for its culms and shoots and the dramatic declines in its native habitats and stand quality indicate that further research that focuses on its germplasm collection and conservation is urgently needed [3,6].

This new information about the diversity in its population genetics demonstrates the degree of success these plants have had in adapting to their altered environments over time. Therefore, it is of critical importance that this knowledge be applied in assessing their conservation value and the status of particular populations when developing management plans [32,33]. Despite dramatic reductions in natural habitat, based on our results, the high genetic diversity is still maintained within populations of D. membranaceus in Yunnan, China. However, the genetic differentiation among the populations and the limited reproductive capability of D. membranaceus in the wild indicate that it is still necessary for us to protect all of the existing natural populations and their habitat in Yunnan, China. At the same time, germplasm collection and conservation in the Lancang-Mekong River Valley, the distributional center of this species, should be placed at the first and foremost position.

\section{Experimental Section}

\subsection{Plant Materials}

Figure 5. Distribution of extant natural Dendrocalamus membranaceus forests (shaded) and locations of 12 populations sampled in Yunnan Province, China.

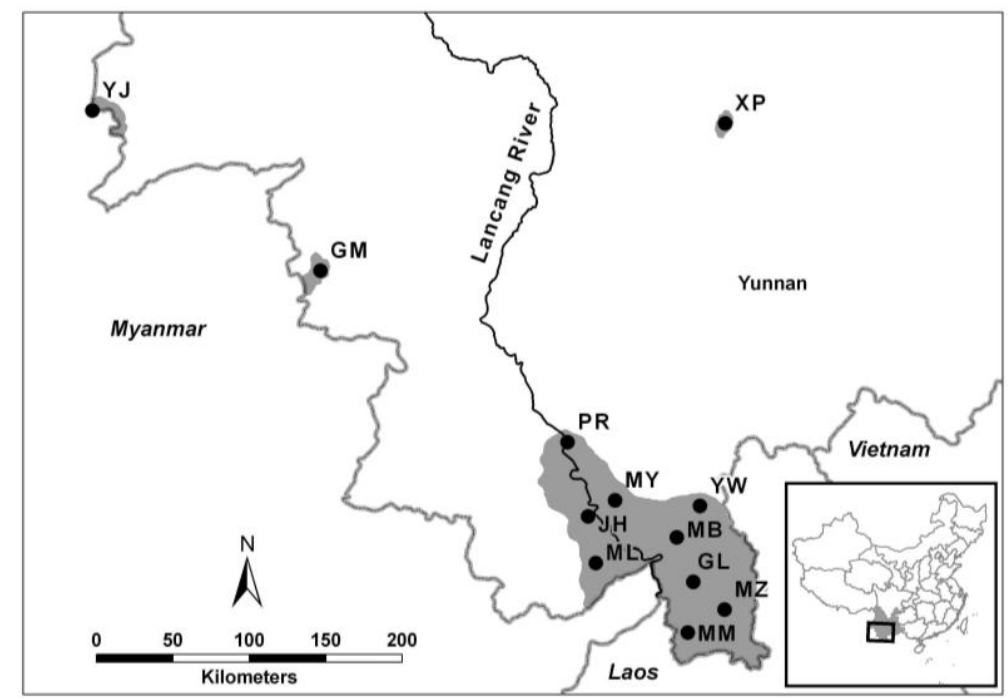

A total of 12 natural populations were sampled from almost all of the main growing regions of Dendrocalamus membranaceus in Yunnan Province, China (Table 1, Figure 5). Leaves were collected from 240 clumps (20 per population) that were at least $100 \mathrm{~m}$ apart at each site. Using the method of McClure [24], we regarded each clump as a potential genet and the culms within as ramets of a clone, 
and we assumed that an assortment of genetic material existed within each population. All of the samples were dried with silica gel and stored at $4{ }^{\circ} \mathrm{C}$ prior to DNA extraction. Vouchers for each population were deposited at the Herbarium of the Southwest Forestry University (SWFC), Kunming, Yunnan, China.

\subsection{Total DNA Extraction}

Genomic DNA was extracted according to the CTAB protocol [34]. The quality of DNA was determined using $1.0 \%$ agarose gels. The purified genomic DNA was quantified using a BioRad Smartspec3000 UV-Vis spectrophotometer.

\subsection{ISSR PCR Amplification}

Genomic DNA was PCR-amplified using ISSR primers obtained from the Biotechnology Laboratory, University of British Columbia (Vancouver, Canada). Amplifications were performed using an ABI 2720 Thermal Cycler (Applied Biosystems, USA). The $20 \mu \mathrm{L}$ mixture contained $10 \mathrm{ng}$ of template DNA, $2.0 \mu \mathrm{L}$ of $10 \times$ PCR buffer, $1.8 \mathrm{mM} \mathrm{MgCl}_{2}, 0.1 \mathrm{mM}$ dNTPs (TAKARA, Dalian, China), $2 \%$ formamide, $100 \mathrm{nM}$ of each primer, 1.5 units of Taq polymerase (Fermentas), and double-distilled water. The cycling conditions included an initial denaturation at $95{ }^{\circ} \mathrm{C}$ for 3 min; then 40 cycles of $95{ }^{\circ} \mathrm{C}$ for $30 \mathrm{~s}, 50{ }^{\circ} \mathrm{C}$ for $30 \mathrm{~s}$, and $72{ }^{\circ} \mathrm{C}$ for $2 \mathrm{~min}$; and a final extension at $72{ }^{\circ} \mathrm{C}$ for $10 \mathrm{~min}$. The PCR products were electrophoretically separated using $2.0 \%$ agarose gels buffered with 0.5× TBE. A 100-bp DNA ladder (Fermentas) was used as a size marker. The PCR reactions were repeated twice to ensure reproducibility. After staining with ethidium bromide $\left(1 \mu \mathrm{g} \cdot \mathrm{mL}^{-1}\right)$, the DNA fragments were identified by software Lab Works Software 3.0 [35] for gel documentation.

\subsection{Data Analysis}

Only distinct, reproducible, well-resolved fragments were scored as present (1) or absent (0) for each marker, and were displayed as part of a binary matrix. The data matrices were analyzed using POPGENE version 1.31 [36]. The following genetic parameters were determined: The percentage of polymorphic bands (PPB), expected heterozygosity $\left(H_{\mathrm{E}}\right)$, coefficient of gene differentiation $\left(G_{\mathrm{ST}}\right)$, genetic distance $(D)$, and Shannon diversity index $(S)$. An analysis of Molecular Variance (AMOVA program Version 1.55) [37] was performed to describe the genetic structure and variation among the populations and among the individuals. The number of private bands was calculated using GenAlEx 6.1 [38].

To visualize the genetic relationships among the populations, we constructed a dendrogram based on Nei's [39] genetic distance $D$, implementing an unweighted pair-group method of cluster analysis that used arithmetic averages (UPGMA) and the software program NTSYS-PC V2.1 [40]. To test for putative correlations between the genetic distances and geographic distances among the populations, we performed Mantel tests using TFPGA software [41], computing 1000 permutations. 


\section{Conclusions}

In summary, high genetic diversity and lower genetic differentiation were detected among the Dendrocalamus membranaceus populations in Yunnan. A large proportion of the genetic variation (78.95\%) resides among individuals within the populations, whereas only $21.05 \%$ exist among the populations. No significant correlation was found between the genetic and geographic distances among the populations. Considering that D. membranaceus is a monocarpic and has prominently low sexual reproduction, we propose to implement in situ conservation measures for all of the populations and collect sufficient samples for ex situ conservation. Our results are also of important significance for the resource conservation of D. membranaceus in its main natural habitat, the Lancang-Mekong River Valley.

\section{Acknowledgments}

The authors thank three anonymous reviewers for their valuable comments and suggestions. This work was funded through projects of the State Forestry Administration of China (grant No. 2008-4-30), the National Natural Science Foundation of China (31070593), International Centre for Bamboo and Rattan (1632009014), Applied Basic Research Program of Yunnan Province, China (2010CD141), and the Knowledge Innovation Program of the Chinese Academy of Sciences (KSCX2-YW-G-035-1).

\section{References}

1. Li, D.Z.; Stapleton, C. Dendrocalamus. In Flora of China; Wu, Z.Y., Raven, P.H., Hong, D.Y., Eds.; Science Press: Beijing, China; Miss. Bot. Gard. Press: St. Louis, MO, USA, 2006; Volume 25 (Poaceae), pp. 39-46.

2. Yi, T.P.; Shi J.Y.; Ma L.S.; Wang, L. Iconographia Bambusoidearum Sinicarum; Science Press: Beijing, China, 2008; pp.184-219.

3. Dransfield, S.; Widjaja, E.A. Plant Resources of South-East Asia, (No. 7): Bamboos; Backhuys Publishers: Leiden, The Netherlands, 1995; pp. 85-87.

4. Li, D.Z.; Hsueh, C.J. A study on the genus Dendrocalamus Nees from China. J. Bamboo Res. 1988, 7, 12-13.

5. Xue, J.R.; Yang, Y.M.; Hui, C.M.; Li, R. Bamboo Resources and Development Research of Yunnan; Yunnan Science and Technology Publishers: Kunming, China, 1995; pp. 7-11.

6. Hui, C.M.; Yang, Y.M. Timber Bamboos and Industrialized Utilization; Yunnan Science and Technology Publishers: Kunming, China, 1998; pp. 27-30.

7. Ziegler, A.D.; Fox, J.M.; Xu, J.C. The rubber juggernaut. Science 2009, 324, 1024-1025.

8. An, M.Y.; Yang, H.Q.; Yang, Y.M.; Sun, M.S. Preliminary study on resources and protection of natural Dendrocalamus membranaceus forest in China. J. Shandong For. Sci. Tech. 2010, 40, 111-113.

9. Soderstrom, T.R. Some evolutionary trends in the Bambusoideae (Gramineae). Ann. Missouri Bot. Gard. 1981, 68, 15-47. 
10. Scientific Database of China Plant Species. Available online: http://botanica.cn/eflora/view/search/ Chs_contents.aspx?1_name=Dendrocalamus\%20 membrana ceus\%20Munro (accessed on 23 October 2011).

11. Li, X.L.; Lin, R.S.; Fung, H.L.; Qi, Z.X.; Song, W.Q.; Chen, R.Y. Chromosome numbers of some caespitose bamboos native in or introduced to China. Acta Phytotaxon. Sin. 2001, 39, 433-442.

12. Abbott, R.J.; Ireland, H.E.; Rogers, H.J. Population decline despite high genetic diversity in the new allopolyploid species Senecio cambrensis (Asteraceae). Mol. Ecol. 2007, 16, 1023-1033.

13. García-Verdugo, C.; Fay, M.F.; Granado-Yela, C.; de Casas, R.R.; Balaguer, L.; Besnard, G.; Vargas, P. Genetic diversity and differentiation processes in the ploidy series of Olea europaea L.: A multiscale approach from subspecies to insular populations. Mol. Ecol. 2009, 18, 454-467.

14. Holttum, R.E. The bamboos of the Malay Peninsula. Gard. Bull. Singap. 1958, 16, 1-135.

15. Ohrnberger, D.; Goerrings, J. The Bamboos of the World; Elsevier: Odenthal, Germany, 1986.

16. Du, F.; Xue, J.R.; Yang, Y.M.; Hui, C.M.; Wang, J. Study on flowering phenomenon and its type of bamboo in Yunnan in past fifteen years. Sci. Silvae Sin. 2000, 3, 57-68.

17. Tian, B.; Yang, H.Q.; Wong, K.M.; Liu, A.Z.; Ruan, Z.Y. ISSR analysis shows low genetic diversity vs. high genetic differentiation for giant bamboo, Dendrocalamus giganteus (Poaceae: Bambusoideae), in China populations. Genet. Resour. Crop Evol. 2011, doi:10.1007/s10722-0119732-3.

18. Das, M.; Bhattacharya, S.; Pal, A. Generation and characterization of SCARs by cloning and sequencing of RAPD products: A strategy for species-specific marker development in bamboo. Ann. Bot. (London, UK) 2005, 95, 835-841.

19. Sharma, R.K.; Gupta, P.; Sharma, V.; Sood, A.; Mohapatra, T.; Ahuja, P.S. Evaluation of rice and sugarcane SSR markers for phylogenetic and genetic diversity analyses in bamboo. Genome 2008, $51,91-103$.

20. Lin, X.C.; Ruan, X.S.; Lou, Y.F.; Guo, X.Q.; Fang, W. Genetic similarity among cultivars of Phyllostachys pubescens. Plant Syst. Evol. 2009, 277, 67-73.

21. Golkar, P.; Arzani, A.; Rezaei, A.M. Genetic variation in safflower (Carthamus tinctorious L.) for seed quality-related traits and inter-simple sequence repeat (ISSR) markers. Int. J. Mol. Sci. 2011, 12, 2664-2677.

22. Li, S.; Li, J.; Yang, X.L.; Zhang, W.J. Genetic diversity and differentiation of cultivated ginseng (Panax ginseng C. A. Meyer) populations in North-east China revealed by inter-simple sequence repeat (ISSR) markers. Genet. Resour. Crop Evol. 2011, 58, 815-824.

23. Liu, D.Q.; He, X.; Liu, G.D.; Huang, B.Z. Genetic diversity and phylogenetic relationship of Tadehagi in southwest China evaluated by inter-simple sequence repeat (ISSR). Genet. Resour. Crop Evol. 2011, 58, 679-688.

24. McClure, F.A. The Bamboos, a Fresh Perspective; Harvard University Press: Cambridge, MA, USA, 1966; pp. 1-362.

25. Hamrick, J.L.; Godt, M.J. Allozyme Diversity in Plant Species. In Plant Population Genetics, Breeding, and Genetic Resources; Brown, A.H.D., Clegg, M.T., Kahler, A.L., Weir, B.S., Eds.; Sinauer: Sunderland, MA, USA, 1990; pp. 43-63.

26. Wu, Z.Y.; Lu, A.M.; Tang, Y.C.; Chen, Z.D.; Li, D.Z. The Families and Genera of Angiosperms in China, a Comprehensive Analysis; Science Press: Beijing, China, 2003; pp. 325-328. 
27. Nei, M. Analysis of gene diversity in subdivided populations. Proc. Natl. Acad. Sci. USA 1973, 70, 3321-3323.

28. Loveless, M.D.; Hamrick, J.L. Ecological determinants of genetic structure in plant populations. Ann. Rev. Ecol. Syst. 1984, 15, 65-95.

29. Nybom, H. Comparison of different nuclear DNA markers for estimating intraspecific genetic diversity in plants. Mol. Ecol. 2004, 13, 1143-1155.

30. Janzen, D.H. Why do bamboos wait so long to flower? Annu. Rev. Ecol. Syst. 1976, 7, 347-391.

31. Zhang, W.Y.; Ma, N.X. Vitality of bamboo pollens and natural pollination in bamboo plants. For. Res. 1990, 3, 250-255.

32. Xiao, L.Q.; Ge, X.J.; Gong, X.; Hao, G.; Zheng, S. ISSR variation in the endemic and endangered plant Cycas guizhouensis (Cycadaceae). Ann. Bot. (Lond. UK) 2004, 94, 133-138.

33. Zhang, L.J.; Dai, S.L. Genetic variation within and among populations of Orychophragmus violaceus (Cruciferae) in China as detected by ISSR analysis. Genet. Resour. Crop Evol. 2010, 57, $55-64$.

34. Doyle, J.J.; Doyle, J.L. Isolation of plant DNA from fresh tissue. Focus 1991, 12, 13-15.

35. LabWorks Software, version 3.0; UVP: Upland, CA, USA, 2003.

36. POPGENE, version 1.31; Microsoft Windows-based Freeware for Population Genetic Analysis; University of Alberta: Edmonton, Canada, 1999.

37. Excoffier, L.; Smousse, P.E.; Quattro, J.M. Analysis of molecular variance inferred from metric distances among DNA haplotypes: Application to human mitochondrial DNA restriction data. Genetics 1992, 131, 479-491.

38. Peakall, R.; Smouse, P.E. GenAIEx 6: Genetic analysis in Excel. Population genetics software for teaching and research. Mol. Ecol. Notes 2006, 6, 288-295.

39. Nei, M. Genetic distance between populations. Am. Natural. 1972, 106, 283-292.

40. NTSYSpc, version 2.1; Numerical Taxonomy and Multivariate Analysis System; Department of Ecology and Evolution, State University of New York: Stony Brook, NY, USA, 2000.

41. Tools for Population Genetic Analysis (TFPGA), version 1.3; Department of Biological Science, Northern Arizona University: Flagstaff, AZ, USA, 1997.

(C) 2012 by the authors; licensee MDPI, Basel, Switzerland. This article is an open access article distributed under the terms and conditions of the Creative Commons Attribution license (http://creativecommons.org/licenses/by/3.0/). 